\title{
LINHAS DE (RE)PRODUÇÃO: UM ESTUDO SOBRE OS PROCESSOS DE SUBJETIVAÇÃO ENVOLVIDOS NAS JUVENTUDES TERRITORIALIZADAS COMO GERAÇÃO Y
}

(RE) PRODUCTION LINES: A STUDY OF SUBJECTIVE PROCESSES INVOLVED IN TERRITORIALIZED YOUTHS AS GENERATION $Y$

LÍNEAS (RE) PRODUCCIÓN: UN ESTUDIO DE LOS PROCESOS DE SUBJETIVACIÓN IMPLICADOS EN LAS JUVENTUDES TERRITORIALIZADAS COMO GENERACIÓN Y

\section{Lucimar Rezende Xavier de Almeida* Roberta Carvalho Romagnoli*}

\begin{abstract}
RESUMO
Esta pesquisa investiga os processos de subjetivação da geração territorializada como Y, para investigar quais agenciamentos compóem e influenciam a produção de subjetivação desses jovens, enfatizando suas singularidades e sua relação com o mundo do trabalho. Foi utilizada, como aporte teórico, a esquizoanálise, de Deleuze e Guattari, e como metodologia, a cartografia. Os procedimentos metodológicos usados foram: entrevistas semiestruturadas, diário de bordo e a implicação da pesquisadora. Nossa trajetória envolveu uma análise do pesquisador com o seu campo, no intuito de acessar as tensões existentes, entre elas as relações de forças entre as especialidades "Psicologia organizacional" e "Psicologia do trabalho". Foi feito um exame dos principais pontos de agenciamentos que capturamos: os tecnológicos, de conhecimento e com a internet, bem como suas conexões rizomáticas com os jovens pesquisados e seus efeitos nos processos de sua subjetivação. Concluímos que esse é um processo complexo que ora pende para a reprodução, ora para a invenção.
\end{abstract}

Palavras-chave: Geração Y. Trabalho. Processos de subjetivação. Tecnologia e internet.

\section{ABSTRACT}

This research investigates the subjectivity processes of generation territorialized as $\mathrm{Y}$, to investigate what intercession make and influence

\footnotetext{
Texto recebido em 9 de outubro de 2016 e aprovado para publicação em $1^{\circ}$ de junho de 2017.

Mestra em Psicologia Clínica e Social pela PUC-SP, MBA em Recursos Humanos com Ênfase em Consultoria Interna e Desenvolvimento Organizacional. Atuação na área de recursos humanos desde 2007 em grandes empresas multinacionais, nas áreas de recrutamento e seleção, treinamento e desenvolvimento, comunicação interna, remuneração e Benefícios pelo modelo de consultoria interna. Tem interesse nas áreas de Psicologia Organizacional e do Trabalho, gerações e juventudes, e esquizoanálise. E-mail: lucimarrezende@yahoo.com.br.

** Doutora em Psicologia Clínica pela PUC-SP, professora adjunta III do Instituto de Psicologia da PUC Minas. E-mail: robertaroma@uol.com.br.
} 
the subjectivity production of these young people, emphasizing their singularities and relationship with the world of work and the management. It was used as theoretical support the Schizoanalysis of Deleuze and Guattari, and as methodology the cartography. The methodological procedures used were: semi-structured interviews, the logbook and researcher's implication. Our trajectory has involved analyzing the implication Researcher with his field; the existing tensions in specialty "Organizational Psychology and Labor". It was performed an examination of the major intercession points that captured: the technology, knowledge and with the internet and its rhizomatic connections with young people researched and its effects on their effects on the processes of their subjectivation. We conclude that this is a complex process which now tilts reproduction now to the invention.

Keywords: Y Generation. Labor/work. Subjectivation processes. Technology and internet.

\section{RESUMEN}

Este estudio investiga los procesos de subjetivación de la generación territorializada como Y, para conocer cuales agenciamientos componen e influyen en la producción de la subjetivación de estos jóvenes, enfatizando sus singularidades y su relación con el mundo del trabajo. Fue utilizado como marco teórico, el Esquizoanálisis, de Deleuze y Guattari, y como metodología, la cartografía. Los procedimientos metodológicos utilizados fueron: entrevistas semiestructuradas, diario de registro y la implicación de la investigadora. Nuestra trayectoria envolvió un análisis del investigador con su campo, con el fin de acceder a las tensiones existentes, entre ellas las relaciones de fuerzas entre las especialidades "Psicología Organizacional" y "Psicología del Trabajo". Se hizo un estudio de los principales puntos de agenciamiento que capturamos: los tecnológicos, de conocimiento y con Internet, así como sus conexiones rizomáticas con los jóvenes encuestados y sus efectos sobre los procesos de su subjetivación. Llegamos a la conclusión de que éste es un proceso complejo que en algunos momentos se inclina hacia la reproducción y en otros hacia la invención.

Palabras clave: Generación Y. Trabajo. Procesos de subjetivación. Tecnología e internet.

\section{SOBRE NOSSO OBJETO DE ESTUDO E COMO NOS PROPUSEMOS A CONHECÊ-LO}

Vivemos em um mundo de muitas mudanças. Nas organizações e na sociedade em geral, tem se falado cada vez mais sobre a "geração Y". Oliveira (2011, p. 10) afirma que essa geração "começa a dominar a paisagem em escritórios de empresas de todos os portes, perfis e setores" e, por isso, "é natural que as 
organizações comecem a rever sua maneira de pensar e principalmente seus mecanismos de relacionamento". Nesse cenário, esta pesquisa tem o intuito de investigar os processos de subjetivação dos jovens territorializados como geração Y, buscando rastrear quais agenciamentos compõem e influenciam a produção de subjetivação desta e enfatizar suas singularidades e sua relação com o mundo do trabalho.

A cartografia foi escolhida como método cartográfico porque seus princípios rizomáticos contribuem para a captura dos processos de subjetivação desse grupo de jovens que se fazem em conexôes de redes tecnológicas, como a internet. Assim, essa rede ou essas redes formadas pela internet remetem ao conceito de rizoma de Deleuze e Guattari (1995) que "é aberto, é conectável em todas as suas dimensões, desmontável, reversível, suscetível de receber modificações constantes" (Deleuze \& Guattari, 1995, p. 22).

Em uma cartografia, entende-se que o mapeamento dos processos e dos movimentos da realidade que o pesquisador deve acompanhar não são uma realidade dada, mas sim produzida por quem pretende conhecê-la. Dessa forma, trata-se de metodologia na qual os dados são produzidos e não colhidos, e essa produção se dá no rico encontro do pesquisador com seu campo de pesquisa. $\mathrm{Na}$ cartografia, o foco do pesquisador implica que ele esteja atento para perceber um mundo que já existia como virtualidade e que em sua observação ganha existência ao se atualizar. Essa atenção tem o papel de manter certo "rigor", mas sem tornar um método rígido. Passos, Kastrup, e Escossia (2009) esclarecem, portanto, que "o cultivo da atenção pelo aprendiz de cartógrafo é a busca reiterada de um tônus atencional, que evita dois extremos: o relaxamento passivo e a rigidez controlada" (Passos et al., 2009, p. 48).

Em nossa produção de dados, foram realizadas entrevistas semiestruturadas, utilizadas falas e situações do cotidiano, além da própria imersão da pesquisadora no campo. Conforme mencionado, não se trata de coleta por amostragem, mas, em uma cartografia, temos uma produção de dados, uma vez que o pesquisador é um intercessor singular do plano de forças que compõe o campo de estudo, atento ao que circula entre os entrevistados, ele mesmo e o objeto de estudo.

Sobre os entrevistados, tivemos 3 indivíduos territorializados como geração Y, 2 gestores e 2 que eram Y e gestores. Com relação aos entrevistados, os critérios para inclusão na pesquisa foram: indivíduos que, por cronologia, foram denominados como geração $\mathrm{Y}$, ou seja, que tenham nascido entre o início da década de 1980 e final da década de 1990, ou, no segundo caso, que fossem gestores do primeiro grupo. E esses não foram representantes apenas do campo o qual a pesquisadora estava inserida, uma vez que o critério de inclusão foi apenas 
o da faixa etária. Assim outras pessoas abordadas e que aceitaram participar das entrevistas compõem o grupo de entrevistas. É necessário mencionar que essa opção de escolha foi feita no início da pesquisa e, no decorrer, revelou-se um processo territorializante, conceito da esquizoanálise que é explicado adiante neste artigo. Sendo essa problematização produto atualizado da pesquisa em sua execução e não conhecido de antemão.

No caso dessas entrevistas, elas foram realizadas em locais convenientes para os entrevistados e que tinham condições de privacidade para acontecerem. Além disso, a pesquisa foi ainda aprovada pelo Comitê de Ética em Pesquisa (CEP) sob registro número Certificado de Apresentação para Apreciação Ética (CAAE) 34773214.3.0000.5137, estando em conformidade com o rigor ético na qual se insere.

Além desse grupo, também tivemos as falas daqueles que naturalmente atravessaram o campo, algumas narrativas que surgiram principalmente nas viagens, no caminho de retorno para casa. Era um lugar especialmente produtivo, pois acontecia, em cada dia, a experiência com uma companhia diferente nessas viagens. Fato era que o campo principal situava-se a $120 \mathrm{~km}$ de Belo Horizonte, e a empresa disponibilizava aos empregados transporte especial para ida e volta, transporte do qual eu era usuária. $\mathrm{Na}$ ida, íamos sempre dormindo, porque ainda era madrugada, mas, na volta, interagíamos com as companhias diversas de colegas de trabalho. Era menos formal e mais descontraído, momento no qual os assuntos surgiam espontaneamente.

Sobre o estudo no principal campo de pesquisa, o qual permitiu outras observações além das produzidas pelas entrevistas e que foram registradas no diário de bordo, esse se deu no meu cotidiano de trabalho. Nesse diário de bordo, estão transcritos todos os dados registrados e coletados durante o processo de observação, além das situações que impactaram a pesquisadora e as ressonâncias com o que estava sendo estudado e experimentado. Esse diário teve por intenção ser um dispositivo de registro do plano das forças que emergiram nos encontros que se fizeram no cotidiano da pesquisa. As observações feitas no campo principal foram realizadas durante os meses de novembro de 2014 até fevereiro de 2015, em uma empresa siderúrgica, nas redondezas de Belo Horizonte.

As formas e forças que compuseram o campo maior da pesquisa foram rastreadas em um processo de atualização do campo, no intuito de entender como essas se atualizam na subjetividade do grupo pesquisado: uma siderúrgica multinacional que, pela Classificação Nacional de Atividades Econômicas (CNAE), em sua faceta instituída, enquadra-se no grau de risco nível 4, em uma escala de 1 a 4, ou seja, o mais alto (Instituto Brasileiro de Geografia e Estatística [IBGE], \& 
Comissão Nacional de Classificação Econômica [CNAE], 2015). Uma empresa enquadrada nesse nível de risco adota uma série de procedimentos de segurança do trabalho, com alto nível de rigidez e controle, para atenuar os riscos inerentes à atividade econômica. Por isso, nas áreas produtivas, eram desenvolvidos procedimentos sistemáticos para as atividades laborais, principalmente as relacionadas à produção diretamente. No âmbito da produção, tinham-se riscos de acidentes que, pela natureza, podiam ser até fatais.

Além das normas regulamentadoras do trabalho que regiam os procedimentos de segurança, a área de qualidade, no intuito de garantir o rígido controle de qualidade dos produtos, determinava para organização do trabalho outros procedimentos em conformidade com as normas de qualidade. Essas normas regulamentadoras partiam da premissa de que a qualidade interferia na segurança e que um erro ou um desvio de qualidade no produto podiam causar acidentes catastróficos para o ser humano e a natureza.

Portanto, para além das questôes tayloristas de produção, ${ }^{1}$ devido a necessidades legais e da própria condição para seu negócio, na empresa existiam linhas extremamente duras, tão duras quanto o próprio aço produzido por ela; no entanto imprescindíveis para garantir a manutenção da segurança e da vida. Mas, por outro lado, essa condição de trabalho refletia, consequentemente, em outros aspectos da subjetividade do trabalhador de qualquer nível ali presente, de forma que essas linhas duras aprisionavam a vida, controlavam-na, mas também a garantiam, uma vez que tentavam preservá-la. No dia a dia, essas linhas refletiam e afetavam as subjetividades dos trabalhadores operacionais e dos especialistas de nível superior, e eram carregadas para suas atividades de forma geral.

Apresentaremos nosso marco teórico e os resultados produzidos e tecidos nas conexões entre saberes acadêmicos, experiências, pesquisador e pesquisados, e que nos permitiram conhecer, em parte e provisoriamente, nosso objeto de estudo.

\section{LINHAS DE PRODUÇÃO SUBJETIVA}

Produzir, produzir, produzir, exatamente esse é o sentido. O que se pretende evocar são linhas e processos de produção subjetiva, inventivos ou serializados, conceitos familiares em um ambiente fabril, mas não exclusivos. Para Guattari (1992), a subjetividade emerge de diversas formas de expressão: as artes visuais, a música, o cinema, a religião, ciência, dentre outros dispositivos de produção

O taylorismo se refere a um modelo de gerenciamento criado por Taylor (1856-1915) e que enfatiza a ideia de racionalização do trabalho sustentada pelo processo de divisão do trabalho. $\mathrm{O}$ trabalhador fazia parte de um processo que era medido, cronometrado e sistematizado de forma a ser controlado em seu percurso laboral. Separação entre planejamento e execução. Objetivo de garantir mais produtividade e rentabilidade para o empregador. 
subjetiva heterogêneos. Assim, não é apreendida em um único modelo psicológico que a universaliza, mas deve ser entendida na complexidade e multiplicidade do conjunto de dispositivos que influenciam e a torna única.

Portanto pensar a subjetividade de tal forma amplia a noção de subjetividade tradicional, pois a considera em um sentido abrangente, plural, polifônica, produzida e influenciada por vários agenciamentos coletivos que podem tornar possíveis processos de subjetivação e singularização. Podemos considerar que cada indivíduo e grupo social têm seu próprio sistema de subjetividade, o que Guattari (1992) define como cartografia feita de demarcações cognitivas, míticas, rituais e sintomatológicas, a partir da qual o indivíduo se posiciona em relação aos seus afetos, suas angústias e tenta gerir suas inibições e suas pulsões. Já a subjetivação (singularização/hecceidade) está relacionada com o indivíduo, em seu devir constante, singular, único, mas totalmente atravessado pela multiplicidade de acontecimentos da coletividade. É importante destacar que subjetividade está relacionada com o coletivo, o social; em síntese, Guattari (1992) define a subjetividade como:

O conjunto das condiçôes que torna possível que instâncias individuais e/ou coletivas estejam em posição de emergir como território existencial auto referencial, em adjacência ou em relação de delimitação com uma alteridade ela mesma subjetiva (p. 19).

Essa leitura da subjetividade insiste na complexidade e na não separação do indivíduo das relaçôes que este estabelece com as forças ao seu redor. Assim, podemos pensá-la como um processo de subjetivação que está relacionada com o indivíduo, em seu devir constante, singular, único, mas totalmente atravessado pela multiplicidade de acontecimentos da coletividade. Para Toussaint (2006, p. 53), "os processos de subjetivação vão designar maneiras de viver, agir, interagir e pensar no mundo", e também podem ser chamados de processos de singularização.

Nessa direção, tentamos evitar uma leitura reducionista desses processos, que indicam somente a interioridade, buscando a rede de relaçôes que são tecidas pelos jovens que compóem o grupo estudado. De acordo com Guattari (1992), há um reducionismo da questão da subjetividade tradicional pela padronização desta, por meio de leitura estritamente da linguagem, o que, para ele, exclui as composiçôes enunciativas semióticas, os processos nos quais as subjetividades se autoengendram e se produzem. A subjetividade, para Deleuze e Guattari (1995), é rizomática, termo que tomou emprestado da botânica. O rizoma é multiplicidade que comporta diversidades, vários "e", ele está fora da lógica 
linear arborescente de uma raiz se conectando e se esparramando por todas as direções como uma grama, ele "não começa nem conclui, ele se encontra entre as coisas, "inter-ser", intermezzo" (Deleuze \& Guattari, 1995, p. 37). É espaço intensivo de transformação. O rizoma é feito de linhas e, para Deleuze e Parnet (1998), as coisas e as pessoas também; essas linhas podem ser de segmentaridade, flexíveis ou de fuga.

As linhas de segmentaridade são as linhas duras que nos dizem o que somos. São como as linhas das normas de segurança e de qualidade do nosso campo que podem refletir na própria subjetividade de seus trabalhadores, tornandoas também duras. São os nossos segmentos e territórios. Segundo Cassiano e Furlan (2013, p. 373), "As linhas duras são as linhas de controle, normatização e enquadramento, e através de seus atravessamentos se busca manter a ordem e evitar o que é considerado inadequado a determinado contexto social instituído". Elas são linhas molares de ordem e estabilidade. Essas linhas dão ao indivíduo certa "identidade" e certo formato, "eu sou isso ou aquilo", "sou homem", "sou mulher", sua profissão, seu nome, tudo aquilo que se estratificou, territorializou. De certa forma, como vimos nas questões de segurança pertinentes à preservação da vida, a segmentaridade também é importante nesse contexto. Contudo, para a esquizoanálise, importa que o que territorializou pode ser desterritorializado e reterritorializado, e ainda que essas linhas nos atravessam em todos os sentidos, mas não precisam nos aprisionar.

As linhas flexíveis são linhas migrantes. Elas não buscam territorializar o tempo todo, elas têm certa flexibilidade que a faz diferente tanto das linhas de segmentaridade quanto das linhas de fuga. As linhas flexíveis traçam pequenas modificações, pequenos desvios. Nesse caso, as desterritorizalizações são apenas relativas. Esta pesquisa utilizou-se dessas linhas para visitar territórios ora da Psicologia organizacional, ora da Psicologia do trabalho.

$\mathrm{Na}$ tentativa de modular as forças que atravessam o campo de pesquisa, fezse importante mapear as áreas da Psicologia que observamos a partir dos dados produzidos e fazem parte do cotidiano dos psicólogos que atuam com esses jovens, mas apenas no que tange aos atravessamentos para a pesquisa. A rigor, temos como especialidade para o Conselho Federal de Psicologia a "Psicologia Organizacional e do Trabalho", conforme artigo $3^{\circ}$ da Resolução CFP no $014 / 00$, de 20 de dezembro de 2000. Esse ramo esteve presente desde o surgimento da Psicologia como ciência, primeiramente nomeado como "Psicologia industrial", quando era mais voltado para as técnicas de recrutamento e seleção nos contextos organizacionais. Atualmente, apesar do termo aberto, "Psicologia Organizacional e do Trabalho", Zanelli (apud Achacr, 1994) aponta que ainda há duas tendências de denominação: 
A primeira mais extensiva tem abarcado as contribuições da Psicologia, Sociologia, Antropologia, Ciências Políticas e outras, sob o rótulo amplo de estudos organizacionais. A segunda, incipiente no Brasil, ressignifica e remete-se para a Saúde Mental no trabalho (Achacr, 1994, p. 104).

$\mathrm{Na}$ prática organizacional e acadêmica, é perceptível essa diferença entre os "psicólogos organizacionais" e os "psicólogos do trabalho", existindo, inclusive, certa tensão entre os dois grupos. A disputa surge das diferenças teóricometodológicas quanto à noção de homem, ética e pressupostos ideológicos, e culminam em fazeres e práticas distintas. De acordo com Leão (2012, p. 293), no entanto, suas distintas ênfases constituem um campo de lutas e tensões entre discursos descontínuos e, muitas vezes, opostos e controversos.

Os "psicólogos organizacionais" são aqueles que habitam o universo das organizações, atuando em subsistemas de RH: recrutamento e seleção, treinamento e desenvolvimento, cargos e salários, entre outros. Já a Psicologia do trabalho, segundo Leão (2012, p. 300), é voltada para assuntos como relações de gênero, trabalho informal, trocas econômicas à margem de grandes cadeias produtivas, trabalho de crianças, impactos psicossociais do desemprego, repercussóes dos modelos produtivo na subjetividade dos trabalhadores, saúde e trabalho, etc., e é representada por autores de renome na Psicologia, como Eugene Enriquez, Christophe Dejours e Yves Clot.

Os contornos dados pela implicação do pesquisador no processo desta pesquisa passaram, portanto, pela reflexão sobre o papel do profissional de $\mathrm{RH}$, com base na especialidade da "Psicologia Organizacional e do Trabalho". Esses traçados contornaram todo processo de pesquisa e toda escrita do trabalho, pois não haveria como não escapar por linhas flexíveis que ora atravessam territórios da "Psicologia organizacional", ora atravessam territórios da "Psicologia do trabalho", promovendo um processo de desterritorialização de cada um desses campos de atuação. Tentamos transpor, contudo, os territórios e abri-los para linhas flexíveis e de fuga escaparem, mesmo que de forma ainda inicial e breve, para os processos de desterritorialização engendrados nessa articulação. Para tal, espera-se hoje um profissional que trabalhe as quebras de paradigmas, fomentando processos de desterritorialização, para permitir, nos ambientes de trabalho, a coexistência das singularidades e assim contribuir com ambientes favoráveis à existência das desejadas equipes de alta performance, aquelas em que encontramos competências diversificadas e que se complementam no coletivo da esquizoanálise. 
Por fim, dando sequência à apresentação das linhas, temos as linhas de fuga, que são aquelas que não cessam de fugir, escapam aos territórios, são linhas completamente moleculares. Elas atravessam o agenciamento e o arrastam. Operam pelo processo constante de desterritorialização. São pura criatividade, invenção de si, devir e nos levam para uma direção desconhecida, não previsível e não existente; são linhas completamente nômades. Essas linhas buscam, o tempo todo, as pontas de desterritorialização nos agenciamentos. Para Guattari e Rolnik (2000), os agenciamentos são uma

\begin{abstract}
Noção mais ampla do que as de estruturas, sistemas, forma, etc. Um agenciamento comporta componentes heterogêneos, tanto de ordem biológica, quanto social, maquínica, gnosiológica, imaginária. $\mathrm{Na}$ teoria esquizoanalítica do inconsciente, o agenciamento é concebido para substituir o "complexo" freudiano (p. 317).
\end{abstract}

Nas palavras de Escossia e Kastrup (2005), agenciar é estar no meio, e se agencia com pessoas, bichos, máquinas e coisas, com o de fora, mas em contato com o que está dentro. As autoras explicam que não se trata de imitar. Surge, assim, nesse e em cada agenciamento, algo novo, sempre efeito do coletivo e dupla articulação. $\mathrm{O}$ agenciamento de enunciação é potência, multiplicidade, devir. Os devires, para Deleuze e Parnet (1998), "São geografia, são orientações, direções, entradas e saídas" (p. 10); não são imitações e não se tratam de ajustes a qualquer modelo.

\title{
3. SOBRE AS JUVENTUDES
}

A nomenclatura geração $Y$, que, no nosso entender, é uma forma de tentar endurecer as subjetividades desses jovens, enquadrando-os em um rótulo midiático, é criticada por Bonifacio (2013) e outros autores pela tentativa de rotulação que carregam e por não considerar outros fatores além do cronológico que podem influenciar determinados grupos:

Rotular as pessoas apenas pela geração a que pertencem parece uma avaliação simplicista. Como exposto por Mannheim (1993), além da geração, existem outros fatores influenciadores, como, por exemplo, classe social e história de vida. Todavia, vale ressaltar as características predominantes e os eventos que marcaram cada geração (Bonifacio, 2013, p. 28).

Karl Mannheim, sociólogo que se debruçou sobre a questão das gerações no século passado, em um artigo que escreveu no ano de 1928, traz à tona a questão 
da vivência não linear e cronológica de uma geração, de forma a demonstrar que é antigo o debate sobre o pertencimento geracional. $\mathrm{Na}$ atualidade, outros sociólogos e diversos estudos que passam pelo tema geracional problematizam a questão da geração. Weller (2010) resgata a importância dos estudos de Mannheim para os dias de hoje e afirma:

Nesse sentido, a atualidade deste artigo escrito em 1928 e do conceito de gerações desenvolvido pelo autor recai, entre outros, sobre os seguintes aspectos: 1 . O conceito de gerações de Mannheim e sua acurada elaboração sobre a posição, a conexão e a unidade geracional rompem com a ideia de uma unidade de geração concreta e coesa e nos instiga a centrar nossas análises nas intenções primárias documentadas nas ações e expressões de determinados grupos, ao invés de buscarmos caracterizar suas especificidades enquanto grupo. Perguntar-se pelos motivos das ações desses atores coletivos envolvidos em um processo de constituição de gerações, implica ainda em uma análise da conjuntura histórica, política e social a partir de uma perspectiva que poderíamos situar no nível macro, bem como do conhecimento adquirido pelos atores nos espaços sociais de experiências conjuntivas, e que poderíamos denominar como sendo uma análise no campo micro (pp. 219-220).

Também podemos citar outros autores, como Feixa e Leccardi (2010), que discorrem sobre o tema com base em Augusto Comte e Karl Mannheim, e perpassando por José Ortega y Gasset e Antonio Gramsci, e Juarez Dayrell. Este último prefere trabalhar com conceito de "juventudes", no lugar do conceito de gerações, no plural mesmo, na tentativa de não generalizar os jovens apenas como uma juventude única, pois, para ele, é uma realidade diversificada, baseada "nas condiçốes sociais (classes sociais), culturais (etnias, identidades religiosas, valores) e de gênero, e também das regiōes geográficas, dentre outros aspectos" (Dayrell, 2003, p. 24). Tais aspectos, efeitos de diversidade, são considerados como pontos de agenciamentos que se dão em combinaçóes diversas, pois, para Deleuze e Guattari (1997, p. 50), "as relações, as determinações espaçotemporais não são predicados da coisa, mas dimensões de multiplicidade” e, por isso, podem resultar em subjetividades rizomáticas e singulares. Compreender que múltiplos e diversos atravessamentos produzem $n$ variáveis reforça a ideia de subjetividade rizomática. Nessa direção, o Ser, para Deleuze e Guattari, é o Devir constante de nossos atravessamentos, ora represado em normalizações e classificação, ora fluindo em direção à produção de novas realidades, como salientam Parpinelli e Souza (2005).

As críticas feitas ao termo "geração Y" e à própria noção de geração são relevantes para lembrar que não pretendemos reforçar os estereótipos. No entanto, o termo usado na mídia e recorrente nos ambientes de trabalho foi o que inicialmente chamou atenção para a realização desta pesquisa, conforme 
visto anteriormente, sendo ele dispositivo de interesse comum às pessoas inseridas em contextos organizacionais, como os profissionais de $\mathrm{RH}$, os gestores ou mesmo os empregados. Para um de nossos entrevistados, a única diferença dessa geração para as demais é a informação, e ainda complementa que os pontos de agenciamento relacionados à informação também podem afetar a subjetividade de pessoas de outras idades que estão abertas a isso. Essa é uma grande quebra de paradigma, pensar que não é característica de uma geração e que o que produz essa subjetividade está acessível a todos e é uma linha de fuga, um processo de desterritorialização dessa lógica de geração. No contexto da afirmação do entrevistado mencionado, o recorte cronológico de geração não dá conta de limitar as linhas de fuga que estaria disponível para qualquer pessoa de qualquer época. Em seu exemplo, ele comenta sobre um professor que conhece, já aposentado, o qual se conecta aos pontos de agenciamento dos jovens aqui pesquisados.

A nomeação e classificação com rótulos e estereótipos se referem ao funcionamento que tenta ordenar os fluxos da vida, que são em si heterogêneos. Nesse sentido, o termo "geração Y" é repleto de linhas duras, que são as características atribuídas de forma territorializante pelas produçóes das mass media, ${ }^{2}$ que até aqui usamos com a finalidade de recorte cronológico geracional, e não no sentido estratificado. Nessa perspectiva, ao ler as descrições, buscamos refletir onde nos deparamos com estratos duros, territorializantes da subjetividade e onde podemos encontrar pontos de agenciamento que levem a produçóes subjetivas enriquecidas e imanentes.

Para Oliveira (2011), a geração Y é formada por jovens nascidos entre 1983 e 1994, porém esse período não é um consenso entre estudiosos do assunto. Essa geração territorializada como geração $Y$ também é conhecida por: "Geração Milênio, GenNext, Geração Google, Echo Boom e até Geração Tech" (Lancaster \& Stillman, 2011, p. 19).

Além da geração $\mathrm{Y}$, são mencionadas, em estudos, as seguintes gerações: tradicionalistas, baby boomers, geração $\mathrm{X}$, geração $\mathrm{Y}$ e, atualmente, a geração $\mathrm{Z} .^{3}$

Seguindo nessa linha de rastrear os territórios, Bonifacio (2013) cita outras referências e menciona mais algumas características atribuídas a estes jovens: Para Lipkin e Perrymore (2010), "esses jovens são vistos como individualistas e arrogantes pelas gerações anteriores, contudo, possuem uma consciência social e valores fortes" (Bonifacio, 2013, p. 35).

Lancaster e Stillman (2011) utilizam, para descrever a geração Y, a denominação "fator M", o que seria, para os autores, sete tendências principais que os formaram

O termo mass media se refere aos meios de comunicação de massa e é muito usado por Guattari (1992), no livro Caosmose.

Bonifacio (2013) não menciona a "geração Z", nascidos após o ano 2000, seguindo a sequência cronológica. 
e os acompanham no trabalho: educação no lar, direitos garantidos, significado, grandes expectativas, necessidade de dinamismo, rede social e colaboração.

Muitos adjetivos são dados para os jovens territorializados como "geração Y", entre eles:

Ágeis, ousados, criativos, dinâmicos, antenados, inquietos, proativos, impacientes e com visão holística de todos os acontecimentos e processos. São capazes de realizar inúmeras tarefas ao mesmo tempo. Cresceram jogando videogame, ouvindo música e acessando a internet (Silva, 2012, p. 15).

Os adjetivos são, muitas vezes, rótulos, linhas duras que podem aprisionar a subjetividade em modelos que visam a produzir subjetividades serializadas. Diante do material bibliográfico pesquisado, nota-se que os estudos sobre o tema centram-se nesse aspecto de categorização que, para nossa teoria, são linhas duras, rígidas, que mantêm padrões. As generalizações fazem parte do paradigma da ciência moderna, do empirismo que busca reproduzir um mesmo fenômeno em laboratório.

Em diversos aspectos do nosso cotidiano, podemos capturar a singularidade, embora ainda seja mais enfatizado nas ciências os aspectos de generalização. Podemos pensar nas diferenciaçôes por nosso DNA, nossas íris ou pela digital dos nossos dedos. Esses são exemplos mais tangíveis das diferenças que temos, algo que nos torna singular diante de inúmeros humanos. Portanto, com a subjetividade não seria diferente, apesar das tentativas constantes de generalizações, estas não conseguem, de fato, apreender a subjetividade dos indivíduos, por se tratar cada uma de rizomas únicos e singulares.

Mesmo que grande parte das categorizações apresentadas sejam repletas de territórios e linhas estratificadas com a intenção de produzir uma subjetividade massificada e generalista para a tal geração $Y$, vemos uma tentativa de controle aliada a uma gestão pobre e precária que desvitaliza as potências subjetivas de trabalho dos jovens estudados. Entretanto, em alguns fatores, como na necessidade de dinamismo com o seu fluxo de informações, pelo aspecto diverso que essas podem conter, assim como as redes sociais e a internet, podemos encontrar, como veremos nas entrevistas, pontos de subjetivação, possíveis agenciamentos que chamaram a atenção da pesquisadora a partir das entrevistas e, diante disso, no voo do pesquisador cartógrafo fez o pouso, conforme esse método, como pista de investigação e da atenção do pesquisador. "O gesto de pouso indica que a percepção, seja ela visual, auditiva ou outra, realiza uma parada e o campo se fecha, numa espécie de zoom. Um novo território se forma, 
o campo de observação se reconfigura. A atenção muda de escala" (Passos, et al., 2009, p. 43).

Sobre a identificação desses jovens como nativos da internet: de fato aparece como um diferencial histórico em relação à geração anterior. Contudo, como já falamos, não é nada mais do que um marco histórico; atualmente qualquer subjetividade também pode se agenciar com a internet, independentemente de cronologias. Mas seguimos nossa investigação desse aspecto encontrado na literatura e reforçado pelas falas das entrevistas. Pode ser um ponto de agenciamento (ou não).

Diante de todas as considerações que fizemos, escolhemos por renunciar ao uso territorializante do termo, como expressão de nossa crítica à tentativa de igualar os jovens por determinada faixa cronológica. As linhas de fuga, os fluxos transversais da esquizoanálise vão ao encontro da ideia de juventudes de Dayrell (2003), no sentido que consideram que os jovens, são vários, múltiplos e singulares, cada um traçando ora um percurso próprio na relação com sua época e com sua idade, ora se fechando em formas clonificadas e reprodutivas.

Johansen (2013) criou um esquema que mostra a trajetória de uma suposta Y chamada Ana para tentar explicar um pouco da trajetória desses jovens. Nesse esquema, a jovem Ana é tida como produzida por seus pais, no sentido dos investimentos que esses fizeram em sua subjetividade para que ela fosse uma profissional diferenciada e de sucesso, visto que seus pais lhe proporcionaram uma educação diferenciada. Nesse caso, porém, o diferenciado ficou em relação à geração anterior, porque não somente Ana, mas muitos outros Y também foram produzidos para o mesmo objetivo de ter sucesso profissional. A produção de subjetividade se deu em proporção de coletividade.

Essa expectativa é percebida pelas gerações anteriores como certa arrogância e, portanto, somada ao conhecimento que os $Y$ têm baseado em suas formações e na internet, isso gera incômodo nas geraçóes anteriores pelo fato de os $\mathrm{Y}$ não "respeitarem o conhecimento" que os mais velhos têm. Certamente, conhecimento e experiência são coisas distintas, mas tratando primeiro da questão do conhecimento, sabe-se que a internet tornou disponível um conhecimento que antes poderia ser controlado por pessoas ou instituiçôes. Assim, ela tornou coletivo esse conhecimento e, por conseguinte, muito mais potente para a dimensão subjetiva. O aprendizado é potencializado utilizando os recursos oferecidos pela internet: Google, Youtube, entre outros, e estavam disponíveis para os jovens territorializados como Y desde a infância. Um de nossos entrevistados também destacou isso em sua fala: "Levando em consideração toda a minha dinâmica da infância, de gostar de video game, gostar de tecnologia, essas coisas [...], Internet, internet, outras pessoas". ${ }^{4}$

\footnotetext{
Dados da entrevista. Pesquisa de campo.
} 
Assim a internet emerge como potência em que surgem possibilidades de agenciamento de enunciação para produção de subjetivação como rede, rizoma. Suas conexões que parecem infinitas atravessam a subjetividade, arrastam os estratos, segmentos, pelas forças das linhas de fuga. Esses pontos de agenciamentos produzem subjetivação para os jovens territorializados como geração Y quando se encontram com o novo e estão livres para agenciar com qualquer coisa. Com isso, não significa que o contato com outras pessoas seja anulado, mas ele, muitas vezes, é mediado também pela internet, pelas redes sociais e não tem limite espacial, uma vez que é possível se conectar a qualquer pessoa no mundo todo pela internet. Essas conexões são consideradas por Levy (apud Azevedo, Ferreri, Chaga, Faria, Nascimento \& Almeida, 2015) como relaçôes desterritorializantes que contribuem com trocas de conhecimentos e competências:

Levy (2003) aponta que as relações desterritorializantes via internet possibilitam trocas de conhecimentos e competências, alimentando uma sociabilidade de saber, constituindo o que ele conceitua de "inteligência coletiva” - fundamentada por um dimensão ético-política de reconhecimento do outro em sua inteligência, de valorização do outro como alguém que posso aprender (Azevedo et al., 2015, p. 208).

Dada a redução do número de filhos das famílias brasileiras, conforme tendência mundial, com a entrada da mulher maciçamente no mundo do trabalho, os filhos (muitas vezes filhos únicos ou, no máximo, dois filhos) ficaram em casa cercados por suas companhias eletrônicas: a tevê, os video games e, agora, os tablets e celulares, que eles ganham cada vez mais cedo. As babás ou qualquer pessoa que tenha ficado ali no papel de cuidadores dessas crianças têm deixado que elas fiquem cada vez mais expostas às modernidades tecnológicas. Os pais, por sua vez, quando chegam em casa e não têm mais esse cuidador, ainda deixam seus filhos por mais um tempo expostos a suas companhias eletrônicas para que possam tomar banho, preparar o jantar, ganhar um tempo para fazer algumas coisas. E isso somente fomenta os novos modos de existência tecnológica.

O computador, a internet, o tablet podem provocar deslocamentos subjetivos de invenção do eu, indivíduos conectados 24 horas a seus dispositivos tecnológicos amplificam sua capacidade de pensar e conhecer (ou não). Podem endurecer cada vez mais essas subjetividades, distanciando-as da expansão da vida, clonificandoas em formas de ser pasteurizadas. Carr (2010) menciona, em uma fala de seu livro The shallows: what the internet is doing to our brains (traduzido no Brasil como A geração superficial: o que a internet está fazendo com os nossos cérebros), que alguém ou algo [a internet] tem provocado mudanças no seu cérebro, nas conexões neuronais, mudanças que são provocadas pelo contato com a internet. 
O autor explica que, devido aos vários estímulos que são encontrados nas telas do computador quando navegamos pela internet, os quais servem para capturar nossa atenção e nos fazer clicar em outras páginas, fazem então nossa atenção flutuar e, da mesma forma, dispersar quando não estamos em interação com esse dispositivo. No intuito de investigar os efeitos que são produzidos na subjetividade, esse incômodo, portanto, serve-nos como pista para analisar as mudanças provocadas na subjetividade por meio dessa interação.

Outras modificações também podem ser pensadas com base na interação com a internet. Por exemplo, a facilidade e a velocidade propiciada pela internet a seus usuários e, neste caso, aos nossos pesquisados.

A grande questão é como isso funciona em cada conexão, que efeitos esse excesso de informação produz em cada subjetividade que se conecta nesses fluxos, pois é fato que eles provocaram mudanças, conforme se observa na fala da entrevistada Vanessa:

Com certeza. Eu vejo assim, principalmente o acesso à tecnologia mudou, muda muita coisa. Eles têm acesso a muita informação, tudo muito mais rápido, e aí a relação com a gente também é diferente, né? Eu acho que tem muito mais, é[...] Não tem medo, né, mais eu acho que o principal é o grande acesso que eles têm à informação, que faz com que eles sejam criados de uma forma que eles não tenham muita paciência pra esperar. Eu acho que essa geração, a dele, eles falam que é a $Z$, né[...] (Vanessa). ${ }^{5}$

Vanessa, gestora, e territorializada como geração X por sua faixa etária, em um trecho de sua entrevista, destaca os efeitos da tecnologia para as gerações atuais. Vanessa ressalta que, para as gerações mais jovens, a de seu filho, definido como geração $\mathrm{Z}$, os efeitos estão mais acentuados. Juan, 31 anos, um dos jovens entrevistados, formado em Engenharia Mecânica, também comenta os efeitos dos agenciamentos tecnológicos. Para ele, existe uma facilidade em obter informaçóes com "o advento da tecnologia", através dos smartphones, da internet e do Google. Ele relata que muita coisa que aprendeu foi pesquisando na internet. Assim, segundo o jovem, o conhecimento não depende mais da experiência de alguém para ser transmitido, o dispositivo da internet tomou esse lugar do humano, e agora a conexão para transmissão do conhecimento está à disposição, em um clique.

Outra pista dos efeitos são as velocidades envolvidas nesses fluxos. Elas podem ser um dos dispositivos que provocam efeitos na subjetividade dessa geração. Juan diz: "Antigamente, pra você fazer uma pesquisa, você sentava horas e horas, e lia, e tudo mais. Hoje você pergunta. Você vai fazer um serviço, você pergunta, e o Google te responde, você filtra, aí você vai filtrar o que é verdadeiro" (Juan). ${ }^{6}$ 
Ou seja, uma coisa é sentar horas e folhear vários livros, outra coisa é fazer a pergunta para o Google. No primeiro caso, são horas dedicadas com atenção e paciência; e, no segundo, é só clicar, clicar, clicar.

Uma das identificações para a "geração Y" é que os seus sujeitos constituintes são nativos da internet, uma analogia pertinente, pois implica que a internet foi um advento já presente quando cada um deles tinham nascido. Esse é um dispositivo de subjetivação mais específico do período cronológico em que eles nasceram, um diferencial histórico em relação à geração anterior, um fora que, como a própria língua, mistura-se com o dentro. Consideramos, portanto, nesta pesquisa, que esse aspecto encontrado na literatura e reforçado pelas falas das entrevistas pode ser um ponto de agenciamento.

Em um artigo chamado Experimentação política da amizade em comunidades da internet a partir da teoria dos afetos em Espinosa, Azevedo et al. (2015) discutem o assunto das novas formas de se relacionar via internet. No texto, os autores falam dos processos de desterritorialização que essas experiências promovem e apontam ainda alguns perigos de controle que podem existir. Trata-se de um artigo recente, o qual aborda as transformações que essas amizades podem gerar na subjetividade. Para os autores, a amizade mediada pela internet é um "espaço de diálogo voltado para compartilhamentos das inesgotáveis opiniōes concernentes aos assuntos humanos que está em jogo nas relações entre amigos na internet" (Azevedo et al., 2015, p. 218). Os usos diversos da internet e as novas formas de existência que ele possibilita são comumente criticados por pessoas das gerações anteriores. É natural que as geraçōes anteriores questionem as novas formas de existência das gerações que surgem e constantemente renovam os modos de ser. Existe uma tendência em achar que seu modo de existência é o mais correto ou o melhor, mas não se trata disso, os modos de existência simplesmente são, acontecem. Em nossas entrevistas, o grupo denominado como Y, em sua maior parte, ressaltou e criticou as diferenças em relação à geração mais nova.

A intenção dessa análise élançar o olhar sobre o processo envolvido na produção de subjetividade desses jovens que compõem o que usualmente se denomina geração $\mathrm{Y}$, buscando entender os engendramentos que os produzem, de forma que possamos lidar com suas singularidades. Buscamos o percurso histórico de criação, trajetórias de formação e entrada no mundo do trabalho, rastreando os pontos de agenciamento tecnológicos que foram identificados como parte do momento histórico dessa geração e produtores de suas subjetividades. $\mathrm{Na}$ produção de subjetividade esquizoanalítica, a interposição e os encontros da subjetividade humana se encontram com o não eu (o tecnológico) e podem tornar-se maquínicos, conforme podem colocar a engrenagem da vida para funcionar, para produzir diferenças e atualizar virtualidades. 
Fonseca, Neves, Amador, e Kirst (2008, p. 508) enfatizam "a potência das máquinas na produção de nossos modos de subjetivação e de inteligência" e a introdução maciça de novas tecnologias impactando diretamente no processo de trabalho. Observe a fala de Lucas (nome fictício):

Máquinas, equipamentos e $[\ldots]$ e $[\ldots]$ e $[\ldots]$ eletrônicos $[\ldots]$ acho que tudo, tudo, entendeu? Tudo, por exemplo, desde... desde, sei lá, de uma tecnologia num carro a uma televisão LCD, entendeu? Acho que [...], sei lá, acho que cinco anos atrás ninguém tinha uma televisão de tela plana. Era raro você ter uma televisão de tela plana. [...] Olha onde a gente tá, em LED, entendeu, eu acho que, sei lá, quando eu entrei aqui, eu conheci tanta coisa nova, tanta gente nova, gente de todo lugar, entendeu, e, sei lá, é, abriu o meu campo de visão assim. Foi muito isso. Eu acho que isso que acontece, internet [...] (Lucas). ${ }^{9}$

A partir da fala desse entrevistado, dialogamos com Fonseca et al. (2008, p. 508), os quais chamam a atenção para o mundo da tecnicidade, que se revela como a "expressão concreta dos movimentos do pensamento humano, engenhoso e criador". Por essa reflexão, somos levados a lembrar que, por trás de qualquer invenção-máquina ou de qualquer outra invenção, está o humano. Toda lógica de funcionamento de uma máquina foi pensada por um humano, e essa mesma máquina inumana, se desconectada de seu criador inicial, busca se conectar com outros humanos. Essa segunda interação retoma a primeira em desdobramentos do dentro-fora-dentro. Mesmo que, por pano de fundo, tenhamos a máquina de produção capitalística, ainda sim esses agenciamentos têm potência criativa e de imanência.

Contudo, se por um lado, a internet e novas formas de tecnologia contribuem para o enriquecimento da subjetividade, por outro Azevedo e Bolomé (2001, p. 209) esclarecem que outros estudiosos ressaltam a utilização da internet como dispositivo de controle:

Autores como Rheingold (1996) e Senra (1993) apontam a nova rede de telecomunicações mundial como uma nova espécie de panóptico que exerce uma vigilância mais pontual, iluminando apenas zonas de interesses em detrimento de outras que ficam na sombra - diferente do panóptico de Bentham, cuja visibilidade era total. De acordo com Senra (1993), trata-se de uma iluminação intermitente que não se dirige mais ao espaço, mas a um alvo a ser operado dentro de um plano específico.

Fonseca et al. (2008) lembram da necessidade que o capitalismo tem de se alimentar das criatividades e de toda forma de inteligência que as faculdades da alma podem produzir. $\mathrm{O}$ trabalho com a internet e os produtos que este pode produzir são produtos da inteligência humana em última instância:

9 Dados da entrevista. Pesquisa de campo. 2015. 
Nesse novo contexto, o que as organizações buscam no trabalhador não é mais a força, conforme ressaltava o conceito de "força de trabalho", nem o controle do corpo obediente (o corpo dócil e disciplinado, examinado por Foucault); mas a "alma” - as produções do espírito, como o conhecimento, a criatividade, a inteligência, o engajamento subjetivo, a responsabilidade -, conforme observam Negri e Hardt (2001, p. 11) a respeito da transição do fordismo ao pós-fordismo: não é mais um corpo que pode ser posto a trabalhar, não é mais uma alma que pode viver independentemente de valores e paixões. Desta vez é a alma que é posta a trabalhar, e o corpo, a máquina são o seu suporte (Fonseca et al., 2008, p. 505).

Visto que foi necessário investir em subjetividades enriquecidas para sustentar o sistema capitalístico, as formas de controle da subjetividade ficaram mais sutis, travestidas de espaços estéticos coloridos, mais alegres e belos, porém, não raras as vezes, da mesma forma institucionalmente controladores. Essa é uma linha tênue que gera um impasse para o sistema capitalista, que, ao mesmo tempo em que precisa dessa subjetividade enriquecida, esforça-se para mantê-la prisioneira mediante formas sutis de controle que emergem nesse novo modelo.

E, apesar de o foco inicial dessa pesquisa ser a produção de subjetividade no sentido da singularização, salientamos que essa produção inventiva pode ou não ocorrer e, mesmo não sendo o nosso objetivo, faz-se necessário mencionar como a produção de subjetividade pode ser corrompida pelo capital. Portanto não ignoramos nesta pesquisa que existe um forte investimento por parte desse sistema capitalístico atuando nos processos de subjetivação. Isso significa que temos de fazer o questionamento de quando o produto da subjetividade é mera reprodução de linhas de produção serializada de subjetividade e quando são potências na singularidade de cada caso, cada conexão.

$\mathrm{Na}$ fala de Lucas, um dos entrevistados, um jovem, solteiro, que começou a trabalhar aos 17 anos, esse atravessamento começou no curso técnico. Dessa forma, quando temos o encontro desses jovens com o agenciamento trabalho, eles já chegam com a subjetividade modelada a partir do encontro que tiveram com todas essas possíveis conexões de máquinas (Guattari \& Rolnik, 2000). "É desde a infância que se instaura a máquina de produção de subjetividade capitalística" (Gattari \& Rolnik, 2000, p. 40), e, dessa forma, o capitalismo produz maneiras de se manter. Guattari e Rolnik haviam advertido sobre os apelos para investir em uma subjetividade serializada.

Romagnoli (2007) aponta a corrupção subjetividade devido aos efeitos de um mecanismo perverso do capitalismo, o qual cria um ponto central para sua manutenção, estabelece territórios-padrōes e torna a subjetividade sua mercadoria de consumo. Mais uma vez, voltaremos também à análise de geração e vivências de determinado momento histórico. Podemos concluir 
que os dispositivos de agenciamento mencionados como agenciamentos de enunciação, que são os inventivos, aqueles nos quais nos detemos com maior foco e atenção nesta pesquisa, a saber: conhecimento e tecnologias, existem, mas não são realidades lineares. Existem outros dispositivos, que podem ser rastreados, depende da atenção do pesquisador cartógrafo. Nessa pesquisa, a atenção pousou em determinado ponto e capturou vivências demarcadas em seu recorte. Se desviei no princípio, o foco do leitor para a existência e atualização da subjetividade-trabalhador, outras culturas com outros agenciamentos é/ou seria capaz de produzir qualquer tipo de subjetividade. O ser devir é potência de vida.

Dessa forma, direcionando novamente a nossa atenção para a força pulsante dos corpos e o potencial de desterritorialização (as suas linhas de fuga que escapam o tempo todo e provocam processos de desterritorialização), uma vez que tudo é muito fluido, líquido e, mesmo que reterritorializem, são linhas de velocidade que provocam mudanças constantes. Os processos de desterritorialização para esses jovens são intensificados ainda pela velocidade que as mudanças acontecem:

A rápida mudança tecnológica dissolve a ordem tradicional do tempo. Os indivíduos tentam compensar essa perda aumentando a demanda de formação, refletida no conceito de "educação permanente" [...] Na sociedade da alta velocidade o tempo mesmo se converte em objeto de aceleração (Garcia apud Silva, 2013, p. 25).

Para Teixeira e Barros (2009), o trabalho pode atuar como agenciamento na produção de subjetividade e nos processos de singularização. Considerando o ponto de vista das autoras, o trabalho pode ser um dispositivo dos processos de subjetivação pela apropriação não mecânica da atividade de trabalho, e, dependendo de como os dispositivos tecnológicos estão conectados, eles podem ser considerados como produtores de subjetivação. Esse acoplamento tecnológico dependerá da capacidade de invenção de si e de novas formas de existência, para ser considerado como agenciamento produtor de subjetivação, pois não será em todos os momentos que ele produzirá modos de existência que afirmem a vida como potência criadora.

Esse agenciamento, intermezzo, remete à dimensão molecular e invisível que se estabelece entre o homem e a máquina, e tudo o que circula e afeta nesta dimensão. No filme Jobs (Stern, 2013), o personagem John Sniff diz para Steve Jobs que achava que ele (Steve Jobs) "acreditava que o computador, ou o walkman, ou o que quer que fosse, deveria ser uma extensão natural do indivíduo”. Essa interação pode ser um exemplo de agenciamento, quando, em seu encontro homem e máquina, ela produz novas formas de singularização, nesse caso não somente humano, e nem máquina, mas a fusão dos dois. Outro devir, devir 
homem/computador, humano/máquina. Esse agenciamento tecnológico se faz especialmente importante nesta pesquisa, pois é um dos principais dispositivos identificados nas entrevistas, que agencia com os jovens pesquisados, e que lhes atribuem caracteres tão diversos. São as "alianças amigáveis, pelas quais o mundo e os homens se desdobram em novos possíveis" (Fonseca et al., 2008, p. 508).

Contudo há subjetividades serializadas que se territorializam em categorias profissionais, como os territórios dos profissionais de Engenharia, de profissionais de TI, que, apesar de toda possibilidade de conexão com o plano de imanência, restringem-se à atuação de sua área e aos estereótipos criados para reforçar essa identidade. É como dizer "engenheiro é bom com números e não com pessoas", ou que alguém de Humanas, como os psicólogos, "não são bons com números". Ou se deixar modelar pela rigidez da programação que se faz para as máquinas e para os computadores. Se por um lado, a internet pode oferecer linhas de fuga para a mente, por outro, quando a face maquínica domina, a subjetividade pode ser cristalizada.

Falamos de singularidades quando esses jovens passam por processos de subjetivação e, independentemente da área de atuação ou formação, estão em processos constantes e incessantes de produção subjetiva. Além disso, no encontro com os pontos de agenciamentos que mencionamos nesse sentido, esses jovens vivem em o devir-máquina, devir-computador, devir-internet, devirtecnológico, pois, nesse caso, o sujeito não é um nem o outro, não é máquina nem humano, mas outro efeito, produto do agenciamento.

\section{CONSIDERAÇŌES FINAIS}

Ao rastrear o plano de forças que perpassa a territorizalizada geração $\mathrm{Y}$ em sua articulação com o mundo do trabalho, as singularidades desses jovens, observamos certos endurecimentos como o do próprio termo e os adjetivos e características vistos na teoria que refletem nos ambientes de trabalho e que reforçam o termo midiático.

Sem a intenção generalizante, capturamos alguns pontos que poderiam ser de agenciamento para esses jovens e seguimos os processos de subjetivação que esses produzem. Deparamos com a tecnologia, o conhecimento e a internet como os principais pontos de agenciamento, e esses são a dupla pinça (devir-máquina, devir-computador, devir-internet, devir-tecnológico) que produzem em seu intermezzo as mutações sempre singulares. Sobre as tecnologias e suas interações com o humano, capturamos alguma imanência humano-máquina, pois é uma interação que se retroalimenta e que reflete a capacidade inventiva da inteligência humana, já que toda essa criação máquina tem origem na criação humana. 
Vimos que esses pontos têm potencial rizomático e podem gerar $n$ conexões, ou não, ou as linhas duras e estratos molares podem tornar ainda mais cristalizada a subjetividade-trabalhador dos jovens no trabalho. No entanto não se trata meramente de questão de geração. Os agenciamentos estão aí para quem tiver abertura para conectar-se a eles. Os efeitos e devires desses agenciamentos são inventivos, criativos e inteligentes, mas não deixam de ser fomentados pelas necessidades capitalísticas que, de tempos em tempos, renovam-se.

Buscamos registrar a imanência, as lacunas inventivas dos trabalhadores no trabalho, seja qual fosse sua singularidade, e tomamos o "trabalho como possibilidade de expressão de uma subjetividade em sua diferença" (Barros, Louzada \& Vasconcellos, 2008, p. 15).

Tentamos manter a atenção para percorrer linhas flexíveis entre vieses da Psicologia organizacional e do trabalho (que ora tende para as organizaçóes propriamente dito e ora tende para uma psicologia mais do trabalho) em relação aos jovens estudados. Alternando entre os territórios que habitam o termo, mas estando atento às linhas de fuga que arrastam esses territórios e abrem para os processos inventivos, além das linhas duras dos adjetivos que pretendem capturar e cristalizar as subjetividades, para com isso favorecer a compreensão de que os indivíduos não podem ser aprisionados na dureza que por vezes capturamos nos territórios habitados pelo termo. Pensamos nos possíveis pontos de agenciamentos com possibilidade de articulações de agenciamentos e devires que podem ou não serem produzidos na dimensão da subjetividade.

Também é de extrema importância continuar essa pesquisa no que diz respeito à produção de subjetividades serializadas, o que pode acontecer quando não ocorre processos de subjetivação inventivos, uma vez que, no contexto do capital, o enriquecimento da subjetividade tem como foco a própria manutenção do sistema como vimos acima, sem mencionar que é necessário conhecer melhor os possíveis efeitos dessas forças de reprodução atuando na subjetividadetrabalhador, buscando vampirizar as forças da subjetividade e capturá-las para reprodução serializada.

Assim, nem por um instante, pretendemos fechar o assunto, mas, pelo contrário, nosso rastreamento tem modestamente a intenção de promover os processos de desterritorialização por onde a viagem cartográfica nos conduziu e conduzirá. Certamente muito ainda tem a se discutir e problematizar sobre os temas contidos neste artigo, e, por isso, esperamos servir de inspiração para novos pesquisadores-cartógrafos-nômades. 


\section{REFERÊNCIAS}

Achacr, R. (1994). Psicólogo brasileiro: práticas emergentes e desafios para a formação. São Paulo: Casa do Psicólogo.

Azevedo, B. M. de \& Bolomé, S. P. (2001). Psicólogo organizacional: aplicador de técnicas e procedimentos ou agente de mudanças e de intervenção nos processos decisórios organizacionais? Revista de Psicologia, Organizacional e do Trabalho, 1(1), 181-186. Recuperado a partir de http://pepsic.bvsalud.org/ pdf/rpot/v1n1/v1n1a08.pdf

Azevedo, L. G. N. G., Ferreri, M. de A., Chaga, L. C., Faria, W. de S., Nascimento, G. B. \& Almeida, L. M. (2015). Experimentação política da amizade em comunidades da internet a partir dos afetos de Espinosa. Psicologia USP, 26(2), 208-220. Recuperado a partir de http://www.scielo.br/pdf/pusp/ v26n2/0103-6564-pusp-26-02-00208.pdf

Barros, M. E. B., Louzada, A. P. \& Vasconcellos, D. (2008). Clínica da atividade em uma via deleuziana: por uma psicologia do trabalho. Informática na Educação: teoria \& prática, 11(1), 14-27. Recuperado a partir de http://www. seer.ufrgs.br/InfEducTeoriaPratica/article/viewFile/7130/4880

Bonifacio, T. M. de F. (2013). Trabalho, felicidade e sentido para Geração Y na modernidade líquida. (Dissertação de Mestrado). Pontifícia Universidade Católica de São Paulo, Programa de Pós-Graduação em Psicologia, São Paulo.

Cassiano, M. \& Furlan, R. (2013). O processo de subjetivação segundo a esquizoanálise. Psicologia e Sociedade, 25(2), 372-378. Recuperado a partir de http://www.scielo.br/scielo.php?script=sci_arttext\&pid=S0102$71822013000200014 \& \operatorname{lng}=$ pt\&nrm=iso

Carr, N. (2010.) The shallows: what the internet is doing to our brains. New York: W.W. Norton.

Dayrell, J. (2003, setembro/dezembro). O jovem como sujeito social. Revista Brasileira de Educação, 24. Recuperado a partir de http://www.scielo.br/pdf/ rbedu/n24/n24a04.pdf

Deleuze, G. \& Guattari, F. (1995). Introdução: rizoma. In G. Deleuze \& F. Guattari. Mil platôs: capitalismo e esquizofrenia. (Vol. 1). (pp. 11-37). Rio de Janeiro: Ed. 34. 
Deleuze, G. \& Guattari, F. (1997). 1730 - Devir-intenso, devir-animal, devir-imperceptível. In G. Deleuze \& F. Guattari. Mil platôs: capitalismo e esquizofrenia. S. Rolnik, (Trad.) (Vol. 4, pp. 11-114). Rio de Janeiro: Ed. 34.

Deleuze, G. \& Parnet, C. (1998). Diálogos. São Paulo: Escuta.

Escossia, L. \& Kastrup, V. (2005). O conceito de coletivo como superação da dicotomia indivíduo-sociedade. Psicologia em estudo, 10(2), 295304. Recuperado a partir de http://www.scielo.br/scielo.php?script=sci_ arttext\&pid=S141373722005000200017\&lng=pt\&nrm=iso

Feixa, C. \& Leccardi, C. (2010, maio/agosto). O conceito de geração nas teorias sobre juventude. Revista Sociedade e Estado, 25(2), 185-204. Recuperado a partir de http://www.scielo.br/pdf/se/v25n2/03.pdf.

Fonseca, T. M. G., Neves, J. M., Amador, F. S. \& Kirst, P. G. (2008, dezembro). Dos modos de existência das tecnologias: um trabalho sem fim. Fractal, Revista de Psicologia, 20(2), 12-22.

Guattari, F. (1992). Caosmose: um novo paradigma estético. Rio de Janeiro. Ed. 34.

Guattari, F. \& Rolnik, S. (2000). Micropolitica: cartografias do desejo. (6a ed.). Petrópolis: Vozes.

Hersey, P. \& Blanchard, K. H. (1986). Psicologia para administradores: a teoria e as técnicas da liderança situacional. São Paulo: Pedagógica e Universitária.

Stern, J. M. (Direção)(2013). Jobs [ Filme cinematográfico]. Estados Unidos: Dillywood, Five Star Institute, Silver Reel1. (122min, son., color.).

Instituto Brasileiro de Geografia e Estatística \& Comissão Nacional de Classificação Econômica. (2015). Classificação de riscos de segurança, conforme CNAE. Rio de Janeiro: IBGE. Recuperado a partir de http://cnae.ibge.gov.br= $=$ subclasse $\&$ tipo $=$ cnae $\&$ versao $=9.1 .0 \&$ subclasse $=2423701 \&$ chave $=2423-7 / 01$ Johansen, I. (2013, 30 outubro). Porque os jovens profissionais da geração $Y$ estão infelizes. Campinas: Demografia Unicamp. Recuperado a partir de https://demografiaunicamp.wordpress.com/2013/10/30/porque-os-jovensprofissionais-da-geracao-y-estao-infelizes/

Lancaster, L. C. \& Stillman, D. (2011). O Y da questão: como a geração Y está transformando o mercado de trabalho. São Paulo: Saraiva. 
Leão, L. H. da C. (2012). Psicologia do trabalho: aspectos históricos, abordagens e desafios atuais. Estudos Contemporâneos da Subjetividade, 2(2), 291-305. Recuperado a partir de http://www.periodicoshumanas.uff.br/ecos/article/ viewFile/1008/722

Oliveira, S. (2011). Geração Y: ser potencial ou ser talento? Faça por merecer. São Paulo: Integrare.

Parpinelli, R. S. \& Souza, E. W. F. de. (2005, setembro/dezembro). Pensando os fenômenos psicológicos: um ensaio esquizoanalítico. Psicologia em Estudo, 10(3), 479-487

Passos, E., Kastrup, V. \& Escossia, L. da. (Orgs.). (2009). Pistas do método da cartografia: pesquisa-intervenção e produção de subjetividade. Porto Alegre: Sulina.

Resolução CFP no 014/2000, de 20 de dezembro de 2000. (2000, 20 dezembro). Altera e regulamenta a Resolução CFP n. 014/00 que institui o título profissional de especialista em Psicologia e o respectivo registro nos Conselhos Regionais. Brasília: Conselho Federal de Psicologia. Recuperado a partir de http://site.cfp. org.br/wp-content/uploads/2006/01/resolucao2000_14.pdf

Romagnoli, R. C. (2007). A invenção como resistência: por uma clínica menor. Vivência, 32, 97-107.

Silva, A. L. da (2013). Tecnoutopias: as imbricaçôes Homem/máquina na cibercultura. (Dissertação de Mestrado). Universidade Paulista, Programa de Pós-Graduação em Comunicação, São Paulo. Recuperado a partir de https:// www.unip.br/ensino/pos_graduacao/strictosensu/comunicacao/download/ comunic_andersonluisdasilva.pdf

Silva, D. M. I. (2012). A visão da geração Y em relação à sua qualidade de vida no trabalho. (Dissertação de Mestrado). Fundação Cultural Pedro Leopoldo, Programa de Mestrado Profissional em Administração, Pedro Leopoldo. Recuperado a partir de <http://www.fpl.edu.br/2013/media/pdfs/mestrado/ dissertacoes_2012/dissertacao_davson_mansur_irff_silva_2012.pdf

Teixeira, D. V. \& Barros, M. E. B. de. (2009, abril). Clínica da atividade e cartografia: construindo metodologias de análise do trabalho. Psicologia e Sociedade, 21(1), 81-90. Recuperado a partir de http://www.scielo.br/pdf/ psoc/v21n1/10.pdf 
Toussaint, R. B. (2006). Processos de subjetivação no movimento das serventes em Minas Gerais: contribuiçôes da filosofia da diferença. (Dissertação de Mestrado). Pontifícia Universidade Católica de Minas Gerais, Programa de Pós-Graduação em Psicologia, Belo Horizonte.

Weller W. (2010). A atualidade do conceito de gerações de Karl Mannheim. Sociedade e Estado, 25(2), 205-224. Recuperado a partir de http://www.scielo. $\mathrm{br} /$ scielo.php?script=sci_arttext\&pid=S0102-69922010000200004 